International Journal of

Molecular Sciences

ISSN 1422-0067

www.mdpi.com/journal/ijms

Article

\title{
Engineering Cofactor Preference of Ketone Reducing Biocatalysts: A Mutagenesis Study on a $\gamma$-Diketone Reductase from the Yeast Saccharomyces cerevisiae Serving as an Example
}

\author{
Michael Katzberg ${ }^{1}$, Nàdia Skorupa-Parachin ${ }^{2}$, Marie-Françoise Gorwa-Grauslund ${ }^{2}$ \\ and Martin Bertau ${ }^{1, *}$
}

1 Institute of Technical Chemistry and Biotechnology, Freiberg University of Mining and Technology, Leipziger Straße 29; 09596 Freiberg, Germany

2 Department of Applied Microbiology, Lund University, Getingevägen 60, 22241 Lund, Sweden

* Author to whom correspondence should be addressed;

E-Mail: martin.bertau@chemie.tu-freiberg.de; Tel.: +49-3731-39-2384.

Received: 23 February 2010; in revised form: 24 March 2010 / Accepted: 6 April 2010 /

Published: 14 April 2010

\begin{abstract}
The synthesis of pharmaceuticals and catalysts more and more relies on enantiopure chiral building blocks. These can be produced in an environmentally benign and efficient way via bioreduction of prochiral ketones catalyzed by dehydrogenases. A productive source of these biocatalysts is the yeast Saccharomyces cerevisiae, whose genome also encodes a reductase catalyzing the sequential reduction of the $\gamma$-diketone 2,5-hexanedione furnishing the diol $(2 S, 5 S)$-hexanediol and the $\gamma$-hydroxyketone (5S)hydroxy-2-hexanone in high enantio- as well as diastereoselectivity (ee and de $>99.5 \%$ ). This enzyme prefers NADPH as the hydrogen donating cofactor. As NADH is more stable and cheaper than NADPH it would be more effective if NADH could be used in cell-free bioreduction systems. To achieve this, the cofactor binding site of the dehydrogenase was altered by site-directed mutagenesis. The results show that the rational approach based on a homology model of the enzyme allowed us to generate a mutant enzyme having a relaxed cofactor preference and thus is able to use both NADPH and NADH. Results obtained from other mutants are discussed and point towards the limits of rationally designed mutants.
\end{abstract}

Keywords: biocatalysis; 2,5-hexanedione; S. cerevisiae; site-directed-mutagenesis; Gre2p; cofactor preference 


\section{Introduction}

Enantiopure chiral alcohols and especially those with more than one functional group or stereocenter are of increasing importance as building blocks for the synthesis of chiral pharmaceuticals, flavors and agrochemicals, as well as homogeneous catalysts [1-3]. A representative example among the multitude of chiral alcohols is the diol $(2 S, 5 S)$-hexanediol $((2 S, 5 S)-\mathbf{1})$. It is a key building block in the synthesis of chiral ligands used in phospholane based, homogeneous transition metal catalysts like $(R, R)$-Me-DuPhos-Rh which have proven useful in a number of asymmetric hydrogenation reactions [3-5]. Furthermore the chiral diol (2S,5S)-1 is also of use in the synthesis of a variety of chiral pharmaceutical intermediates, agrochemicals and chiral auxiliaries [3,6-9].

In order to satisfy the demand for this chiral building block an efficient synthetic route yielding enantiopure $(2 S, 5 S)-\mathbf{1}$ is needed. Although numerous synthetic strategies have been developed in the past including asymmetric hydrogenation with Ru-BINAP [10], multistep syntheses [4,11,12] and enzymatic resolution of racemates $[13,14]$, the most efficient strategy is direct reduction of prochiral 2,5-hexanedione (3) mediated by dehydrogenases and microorganisms harboring these enzymes, respectively. Biocatalytic reduction of ketones to obtain chiral alcohols is not only efficient in terms of atom economy [15] but also highly selective and environmentally friendly, as it operates under mild reaction conditions $[16,17]$.

Scheme 1. Reduction of 2,5-hexanedione (3) is stereospecifically catalyzed by Gre2p, yielding the chiral building blocks (5S)-hydroxy-2-hexanone ((5S)-2) and (2S,5S)hexanediol $((2 S, 5 S)-1)$ in a consecutive reaction.

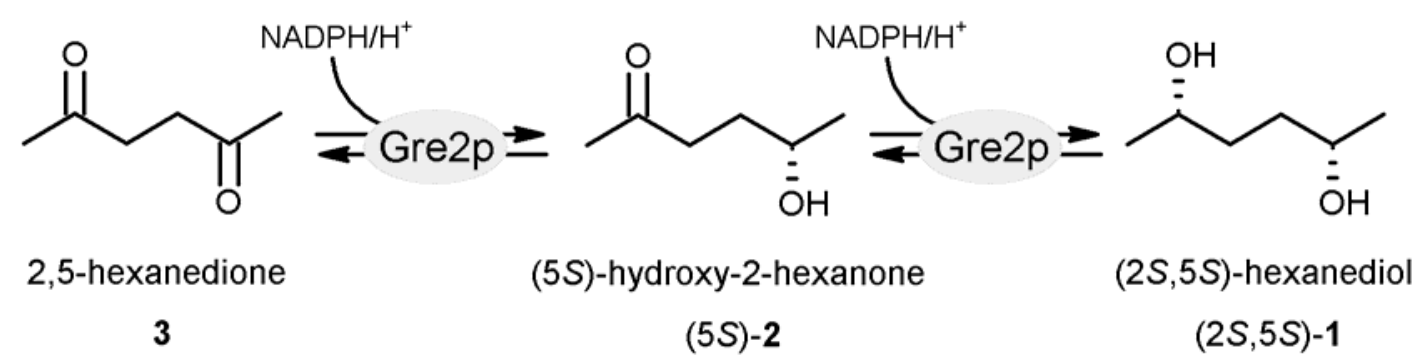

The first biocatalyst reported of being capable of stereoselectively reducing 2,5-hexanedione was the baker's yeast $S$. cerevisiae [18]. Although two other biocatalysts, catalyzing the same reaction with comparable stereospecificity, namely the dehydrogenases ADH-T from Thermoanaerobacter sp. [19] and ADH-A from Rhodococcus ruber [20], have been reported since then, the dehydrogenase responsible for 2,5-hexanedione reduction in S. cerevisiae was identified only recently as the gene product of GRE2 [21]. The latter enzyme - designated Gre2p - is especially interesting when it comes to the production of the monohydroxyketone (5S)-hydroxy-2-hexanone ((5S)-2) which is, just like $(2 S, 5 S)-1$, a valuable chiral building block [22]. However (5S)-2 is far more difficult to obtain than $(2 S, 5 S)-1$, thus it is of significance that it arises as the intermediate in the consecutive $(S)$-selective reduction of $\mathbf{3}$ (Scheme 1) [23]. This intermediate transiently accumulates to up to $90 \%$ the amount of starting material when Gre2p is used as a catalyst, whereas usage of ADH-T and ADH-A, respectively 
yields lower amounts $[23,24]$. Hence the use of Gre2p is advantageous for the efficient production of enantiopure (5S)-2.

But the use of Gre $2 p$ as a biocatalyst is not restricted to reduction of $\mathbf{3}$. The enzyme rather accepts a broad range of substrates including aliphatic and aromatic ketones, chloroketones, diketones as well as $\beta$-ketoesters which are reduced with high stereoselectivity [21,25-32]. The ability of Gre $2 p$ to accept several substrates is also reflected in studies dealing with its physiological role in S. cerevisiae, in which the enzyme is discussed to play a role in the catabolism and metabolism of quite different molecules such as ergosterol [33], isovaleraldehyde [34] and methylglyoxal [35].

It is this broad substrate range which makes Gre2p a highly valuable enzyme in biocatalysis. However if Gre $2 p$ is to be used for bioreductions in vitro additional care has to be taken for cofactor regeneration. Thereby it has to be noted that Gre2p as well as ADH-T and ADH-A prefer NADPH as a cofactor, which is compared to its alternative -NADH- less stable [36] and three times more expensive (according to the 2009 Sigma-Aldrich Catalogue). Hence in terms of biocatalysis a Gre2p variant preferring NADH would be more desirable.

In order to switch cofactor preference of an enzyme, mutagenesis is the method of choice. Especially site-directed mutagenesis has proven useful to alter the cofactor preference of a given dehydrogenase [37-41], in which context it has been reported that in some cases changing even one sole amino acid is sufficient to invert cofactor preference [41-44]. The latter was also achieved for enzymes which are grouped together with Gre2p into the family of short-chain dehydrogenases/reductase (SDR) [38,45-48]. Thus it can reasonably be assumed that an NADHpreferring variant of Gre2p should also be generable by just changing one amino acid. This is in accordance with the literature in which it is reported that within the SDR-family cofactor preference is thought to be determined by one amino acid [49]. Thus we were encouraged to design and generate a tailored Gre2p mutant, which preferably uses NADH as the cofactor of choice through exchanging just one amino acid by rationally guided site-directed mutagenesis. In the case of success this rational approach based on fundamental knowledge of enzyme architecture in SDRs would be much more efficient than generating tailored enzymes through "directed evolution", which relies on labor intensive screening of a huge number of mutants [50]. However it has to be stated that in most cases knowledge on enzyme-activity-relationships is still too limited to rationally design a mutant having the expected properties which in turn renders "directed evolution" a technique yielding the expected results often faster than rational approaches. Nevertheless it should be the aim to gain so much understanding of enzyme architecture that rational creation of an effective and selective enzyme becomes possible. The results of this work contribute to the knowledge on enzyme-activity-relationships in SDRs and thus may take us a bit further to the ultimate goal of rationally designed enzymes.

\section{Results and Discussion}

In order to design a tailored enzyme insights into its structure are a prerequisite. Since a structural model based on X-ray crystallography does not yet exist for Gre2p, a structural model (homology model) based on a homologous dehydrogenase with known crystal structure needed to be constructed. 


\subsection{Homology Modeling of Gre2p}

Within the protein data bank (PDB; www.rcsb.org) the carbonyl reductase I from Sporobolomyces salmonicolor (SSCR; PDB-Code: 1Y1P) shares the highest sequence identity (29\%) and similarity $(18 \%)$ with Gre $2 p$ and thus serves as the models template (E-value $=3 e^{-22} ; 96 \%$ of Gre2p aligned). On the basis of a global sequence alignment between Gre2p and SSCR (Figure 1) it is now possible to assign the secondary and tertiary structure taken from the template SSCR to the primary structure of Gre2p, thus constructing the desired homology model.

Figure 1. Amino acid sequence alignment of the S. cerevisiae dehydrogenase Gre $2 p$ (GRE2P) with Sporobolomyces salmonicolor carbonyl reductase (SSCR) upon which the Gre2p homology model was built. The secondary structure is also given (sec.struc), in which $\mathrm{B} / \mathrm{b}$ indicates $\beta$-sheets and $\mathrm{A} / \mathrm{a} \alpha$-helices. The last line indicates whether an amino acid is conserved between SSCR and Gre2p by using standard symbols.

\begin{tabular}{|c|c|c|c|c|c|c|}
\hline $\begin{array}{l}\text { sec. struc } \\
\text { GRE2P }\end{array}$ & 1 & $\cdots \cdots$ & $\begin{array}{l}\text {. bBBBBBb. } \\
\text { MSVFVSGAI }\end{array}$ & 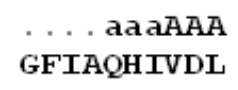 & $\begin{array}{l}\text { AaAa. . bBBB } \\
\text { LLKEDYKVIG }\end{array}$ & $\begin{array}{l}\text { BBBb. . . a a } \\
\text { SARSQEKAEN }\end{array}$ \\
\hline \multirow[t]{2}{*}{ SSCR } & 2 & AKIDNAVLPE & GSLVLVTGAN & GFVASHVVEQ & LLEHGYKVRG & TARS ASKLAN \\
\hline & & & $\star, \star, \star \star \star \star$ & 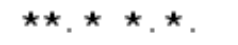 & 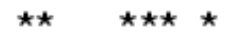 & 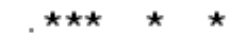 \\
\hline sec.struc & & адАAАааа.. & . bBBBBBb. . & ....... aа & aaa... bBBB & b. . . .----- \\
\hline GRE2P & 40 & LTQTFGN--N & PNFSMEIVPD & ISKLDAFDHV & FQKHGKEIKI & VLHT ASPFCF \\
\hline \multirow[t]{2}{*}{ SSCR } & 52 & LQKRWDAKYP & GRFET AVVED & MLKQGAYDEV & TKGAAGVAHI & ASVVS----- \\
\hline & & $\star$ & $\star \quad . \star \star \star$ & 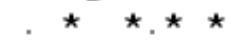 & . & . \\
\hline sec.struc & & -.... аааA & ААААAАAАAА & ААААAа аa - & - . bBBBBb. & $\ldots \ldots-\ldots$ \\
\hline GRE2P & 88 & DITDSERDLL & IPAVNGVKGI & LHS IKKYAAD & CVERVVLTSS & YAAVFDMAKE \\
\hline \multirow[t]{2}{*}{ SSCR } & 97 & -FSNKYDEVV & TPAIGGTLNA & LRAAAATPS - & -VKRFVLTSS & TVSAL-IPKP \\
\hline & & $\ldots \quad \ldots$ & $\star \star . \quad \star$ & $\star$ *. & 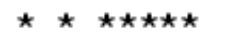 &.$\ldots \star$ \\
\hline sec.struc & & . . . bBBBBb & .... аааААА & aаa...... & аа аАAАAАAА & АААААААААа \\
\hline GRE2P & 138 & NDKSLTFNEE & SWNP ATWE- - & --SCQSDP - - & -VSAYCGSKK & FAEKAAWEFL \\
\hline \multirow[t]{2}{*}{ SSCR } & 143 & NVEGIYLDEK & SWILE SIDKA & KTLPESDPQK & SLWVYAASKT & EAELAAWKFM \\
\hline & & $\star \quad \ldots \ldots \star$ & $\star \star \star \quad$. & $\star \star \star \star$ & $. \quad \star . \star \star \star$ & 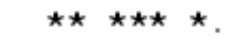 \\
\hline sec.struc & & aa..... $--\ldots$ & BBBBBBBbbB & b. . . . . . & ..... аааAA & Аааа.... аа \\
\hline GRE2P & 181 & EENRDAVKFE & LT AVNPVYVF & GPQMFDKDVK & KHLNT SCELV & NSLMHLSPED \\
\hline \multirow[t]{2}{*}{ SSCR } & 193 & DENK--PHFT & LNAVLPNYT I & GTI-FDPETQ & SGSTSGWMMS & LFNGEVSPAL \\
\hline & & $\star \star \star . \quad \star$ & $\star \star \star \star \star \star$. & $\star \quad \star \star \star$. & . & $\star \star \star$ \\
\hline sec.struc & & aаa..-. bвв & b. . аа аAАAA & АдАаaа... b & BBBBBBb. bB & b. .....aa \\
\hline GRE2P & 231 & KIPELFGGYI & DVRDVAKAHL & VAFQKRET IG & QRLIVSEARF & TMQDVLDILN \\
\hline \multirow[t]{2}{*}{ SSCR } & 240 & $A \amalg M P P-Q Y Y V$ & SAVDIGLLHL & GCLVLPQIER & RRVYGT AGTF & DWNTVLATFR \\
\hline & & . $\quad \star$. & $\star \ldots \quad \star \star \star$ & . $\quad$. & $\star \star . . \quad \star$ & $\star \star$ \\
\hline sec.struc & & aаaа--... & $\ldots \ldots \ldots$ & . bBBb.aaa & AдAаaа.... & .... ааада \\
\hline GRE2P & 281 & EDFPVLKGNI & PVGKPGSGAT & HNTLGATLDN & KKSKKLLGFK & FRILKET IDD \\
\hline \multirow[t]{2}{*}{ SSCR } & 289 & KLYP--SKTF & PADFPDQGQD & LSKFDT AP SL & EILKSLGRPG & WRSIEES IKD \\
\hline & & . $\quad . \star \star$ & $\star \star \star$ & $\cdot \cdot \cdot \cdot$ & $\star \star \star$ & $\star \ldots \ldots . \star \star \star$ \\
\hline sec.struc & & aа.....--- & & & & \\
\hline GRE2P & 331 & TASQILKFEG & $\mathrm{RI}$ & & & \\
\hline SSCR & 337 & LVGSETA -- & - & & & \\
\hline
\end{tabular}


According to the overall sequence identity between model and template the quality and reliability of the model is in the so called "twilight zone", in which false-positive results increase if a secondary structure is deduced from a sequence alignment [51,52].

Although the model may not reliably reflect the whole structure of Gre $2 p$ in detail, it will reliably reflect sub-parts of the enzyme, sharing a higher pair-wise sequence identity and similarity, with SSCR than the whole enzyme does. The latter is especially true for the N-terminal part of Gre $2 p$ which shares $44 \%$ identity and $18 \%$ similarity with SSCR on the sequence level.

Besides local sequence alignments, the local quality of a homology model can also be described through scoring functions such as ProQres [53] or QMEAN [54] (Figure 2). Both algorithms indicate that the homology model of Gre $2 p$ reliably describes its N-terminus. This is of outstanding importance since the N-terminal part of Gre2p, SSCR and other short-chain-dehydrogenases, is responsible for binding and recognizing the nicotinamide cofactor via the so called Rossmann-fold [55-57], which is exactly the target region to be altered by mutagenesis.

Figure 2. Predicted deviation of every amino acid residue in the Gre $2 p$ homology model as assessed by the QMEAN scoring function. QMEAN returns the estimated error of the space coordinates per amino acid residue in Ångström. More reliable regions are characterized by a residue error below $1 \AA$, whereas potentially unreliable regions have an error of $>3.5 \AA$. It is evident from the figure that the N-terminal region (residues 0-50) of the modeled protein structure can be assessed to be quite reliable since the mean predicted deviation in this region is $1.3 \AA$.

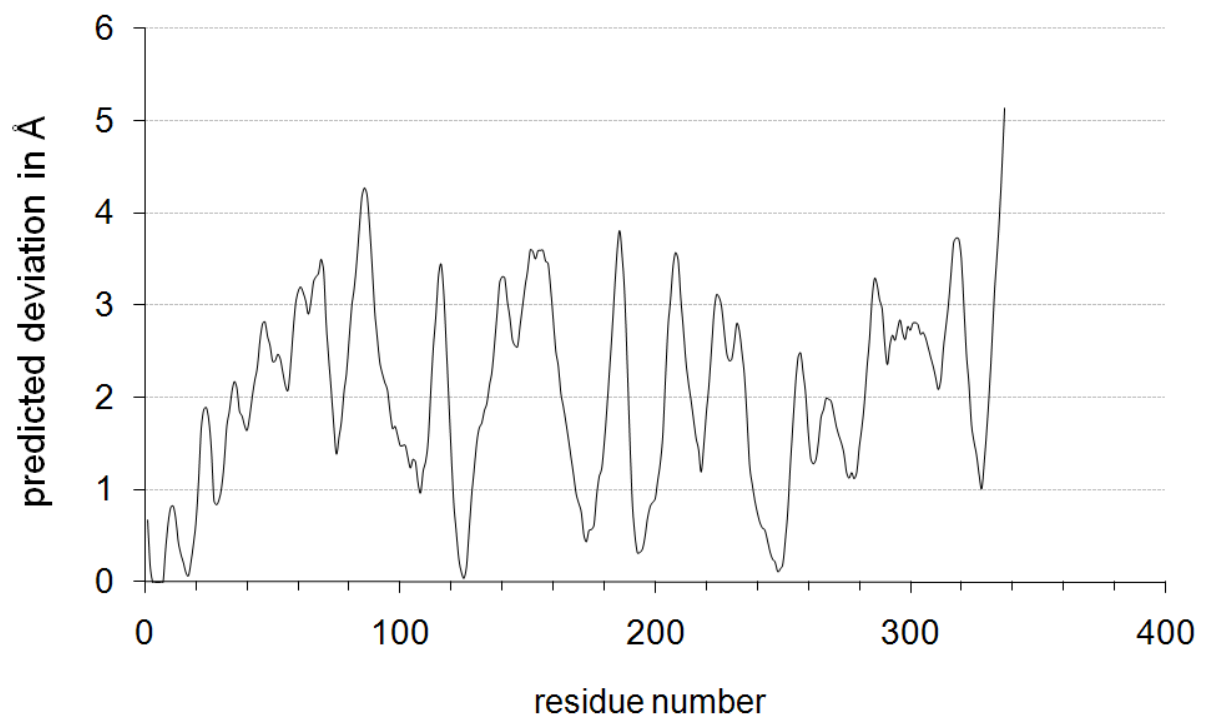

\subsection{Structural Basis of Cofactor Specificity in Gre2p}

By placing $\mathrm{NADP}^{+}$of $1 \mathrm{Y} 1 \mathrm{P}$ into the theoretical structure of Gre2p in silico a first insight into its binding could be obtained. Since it is our aim to change the cofactor preference of the enzyme it is especially important how the dehydrogenase is able to discriminate between NADH and NADPH. As can be seen from Figure 3 Gre2p and SSCR both share a common principle for discriminating NADPH from NADH and preferring the former. Just like it was proposed for the binding of NADPH by 
SSCR [58] Gre2p most probably binds the NADPH 2'-phosphate through electrostatic interactions with an arginine and lysine residue (Arg32, Lys36 in Gre2p; Arg44 and Lys48 in SSCR). As such, formation of salt bridges between the negatively charged phosphate group and the positively charged amino acid side chains stabilizes binding of NADPH, whereas NADH, due to the lack of a negatively charged phosphate group at the 2'-position of adenyl ribose, is not able to undergo such a strong interaction and hence is not able to bind as tightly as NADPH.

Figure 3. (A) Binding of the 2'-phosphate group attached to NADPH's adenyl ribose moiety in SSCR (data from crystal structure PDB-Code: 1Y1P) [42]. (B) This binding motif is conserved in Gre $2 p$ (data from homology model).

A

B
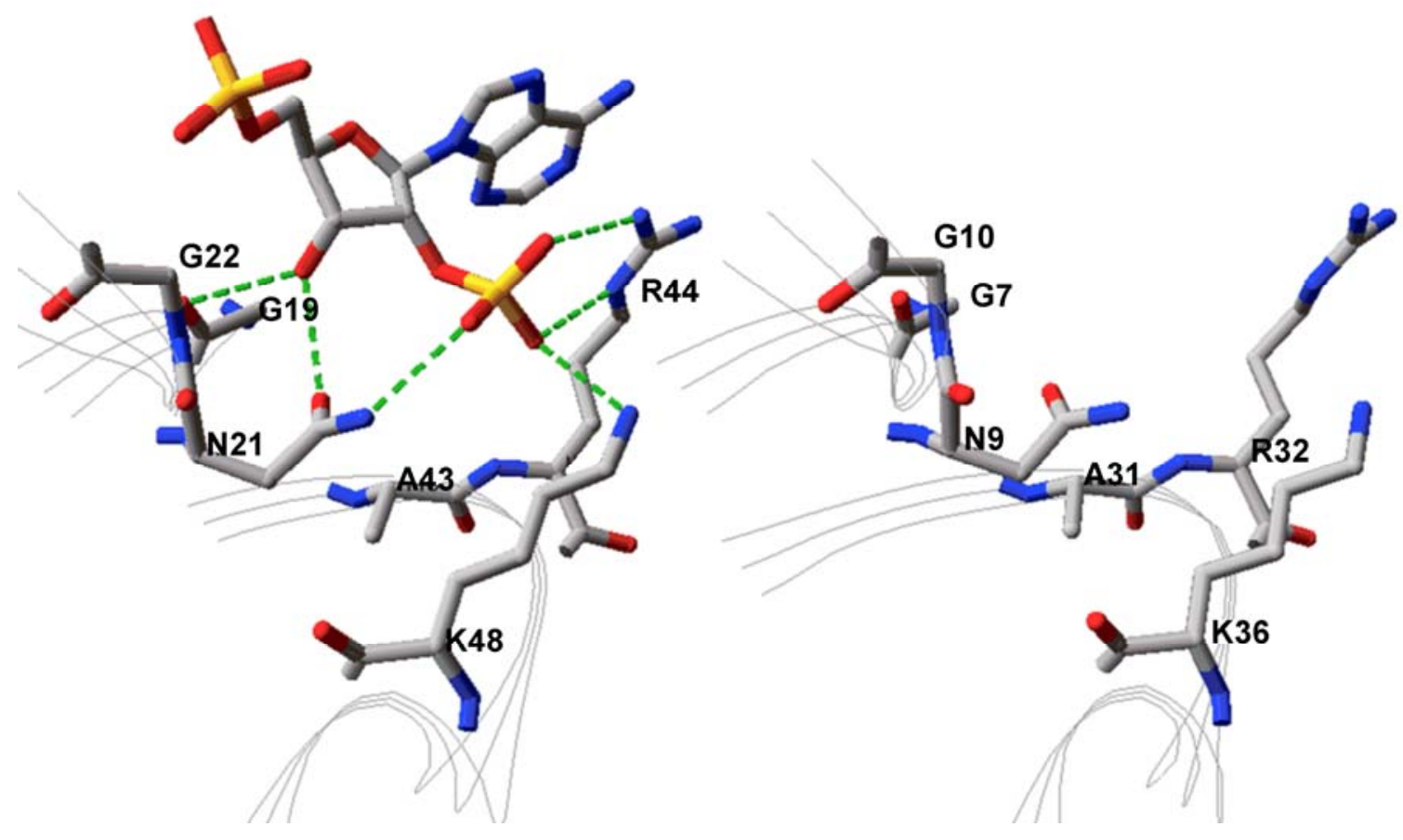

Apart from Arg32 and Lys36 there is an additional amino acid, Asn9, which is in close proximity to the adenyl ribose 2'-phosphate group and thus may stabilize its binding through hydrogen bonds with the 3'-hydroxyl-group and 2'-oxygen atom of the adenyl ribose moiety (Figure 3).

The described phosphate group binding pattern is consistent with the hypothesis of NADPH binding in the family of short-chain-dehydrogenases/reductases (SDR) $[49,56,57]$ to which SSCR and Gre2p belong [46,58]. According to this theory, SDRs in general bind cofactors via a Rossmann-fold [55,59] in which an amino acid having a basic side chain (in most cases Arg, some cases Lys; Arg32 in Gre2p) located in the loop after the second $\beta$-sheet $\left(\beta_{2} \alpha_{3}\right.$-turn, counted from $N$-terminus of protein) confers preference for NADPH. Alternatively this basic amino acid can also be located in the Rossmann-fold specific, so called "glycine rich motif", in which in most of the cases an amino acid having a hydrophilic side chain such as Asn, Gln, Ser, Thr (Asn9 in Gre2p) is found [49,57] (Figure 4). With the latter considerations in mind it should be possible to rationally design a Gre $2 p$ mutant with altered cofactor specificity on the basis of the developed Gre2p homology model. 
Figure 4. Structural basis of cofactor discrimination in dehydrogenases having a Rossmann-fold. Depicted are sections of the NADH preferring $7 \alpha$-hydroxysteroid dehydrogenase from E. coli (left, PDB-Code 1AHH) and the carbonyl reductase from Sporobolomyces salmonicolor (right; PDB-Code 1Y1P). Possible hydrogen bonds are indicated by green lines.

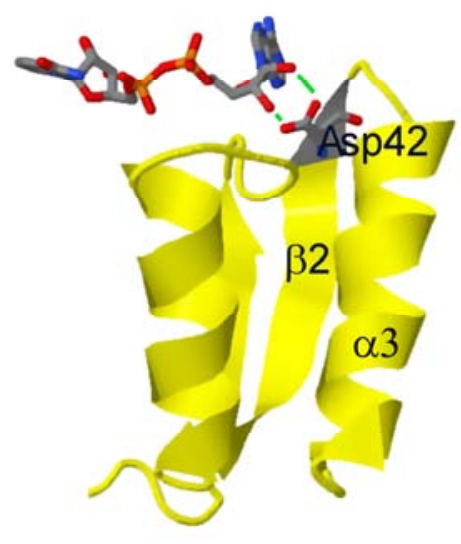

$1 \mathrm{AHH}$

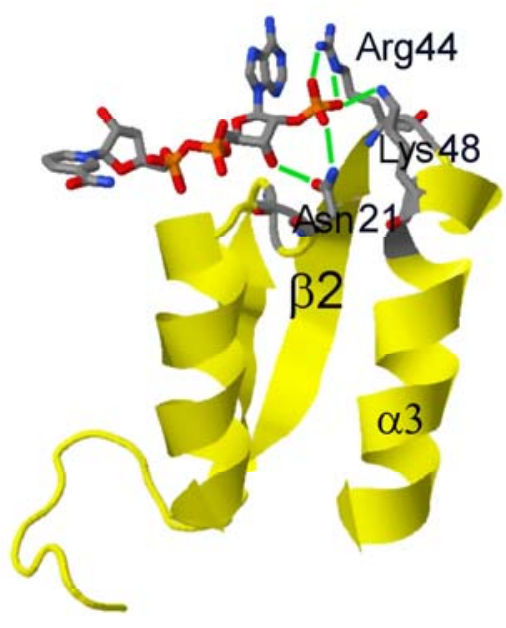

1Y1P

\subsection{Design and Experimental Evaluation of Mutants}

As it is reported that cofactor discrimination in SDRs largely depends on whether a basic amino acid (Arg, Lys) or an acidic amino acid (Glu, Asp) is found in the $\beta_{2} \alpha_{3}$ loop in the cofactor binding Rossmann-fold [49] (Figure 4), it should be possible to interconvert the cofactor preference of a given SDR just by changing this one amino acid. In the case of Gre $2 p$ this would mean exchanging Arg32 with Glu and Asp, respectively. The negatively charged side chain of Glu32 and Asp32, respectively would then lead to the electrostatic repulsion of the negatively charged adenine ribose 2'-phosphate group of NADPH thus constraining its binding. Furthermore the carboxy group of Asp or Glu could form two hydrogen bonds with both 2' and 3'-hydroxy-groups of the adenine ribose of NADH, as such resembling the situation in NADH preferring dehydrogenases (1 AHH in Figure 4).

In practical Gre $2 p$ variants in which Arg32 was replaced by Glu or Asp indeed showed a markedly reduced activity with NADPH as a cofactor (Figure 5), which underlines the importance of Arg32 for binding of NADPH. However compared to the wild-type enzyme NADH-dependent activity was also reduced, rendering this approach ineffective for generating a Gre $2 p$ variant preferring NADH over NADPH.

The loss of activity in short-chain dehydrogenases upon replacement of an arginine analogous to Arg32 in Gre2p has also been reported for salutaridine dehydrogenase from Papaver somniferum [60] as well as for human 17- $\beta$-hydroxysteroid dehydrogenase, which suggests that there is a common reason for this effect. As has been proposed by McKeever et al. [61] arginine can play a dual role. Accordingly, Arg32 in Gre2p would not only be able to establish salt bridges or hydrogen bonds with the 2'-phosphate group of the cofactors adenine ribose moiety but also stabilizes binding of its adenyl moiety through $\pi$ - $\pi$-stacking- and cation- $\pi$-interactions [62]. From this follows that the exchange of 
Arg32 against Glu or Asp will not only lead to electrostatic repulsion of NADPH but also to a weaker binding of adenine cofactors in general.

Figure 5. Impact of mutations in the N-terminal region of Gre $2 p$ on its 2,5-hexanedione reducing activity. Activities are normalized to the wild-type parent $=100 \%$ (control), in which the NADPH-dependent 2,5-hexanedione reductase activity [140 U/g (protein)] is almost 25 times higher than the NADH-dependent one [6 U/g(protein)]. This value is changed to 0.9 in the mutant $\mathrm{N} 9 \mathrm{E}$ indicating that this mutant slightly prefers NADH over NADPH.

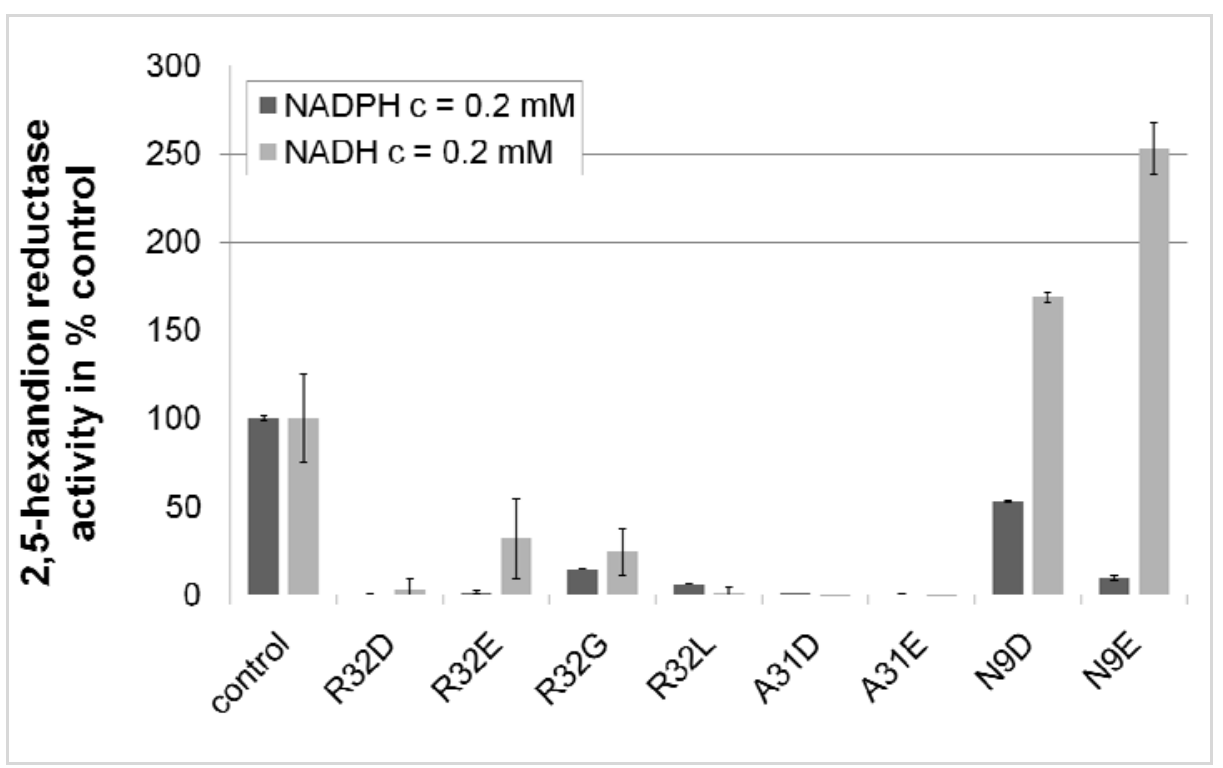

Besides that, the negative charge in the side chain of Glu32 and Asp32, respectively seems to further weaken binding of $\mathrm{NAD}(\mathrm{P}) \mathrm{H}$ cofactors, since substituting Arg32 against Gly and Leu restores some of the enzymes NADPH-dependent activity. This observation furthermore shows that $\pi$-stackingand cation- $\pi$-interactions between Arg32 and the cofactors adenyl-moiety are not indispensable for cofactor binding in Gre2p, although the lack of these interactions remarkably decreases the enzymes activity.

In case of Gre2p Arg32Leu NADPH binding may be facilitated through hydrophobic interactions between Leu32 and the cofactor's adenyl-moiety, whereas glycine at position 32 may increase flexibility of this part of the protein and thus could enable Gre2p to adopt a conformation which allows for more effectively binding the cofactor.

Nevertheless the conclusion has to be drawn that Arg32 is essential for cofactor binding in Gre $2 p$ and other SDRs. As such, substitution of Arg32 in Gre2p and homologous SDRs is not a promising approach for generating an NADH-preferring variant of any of these enzymes.

Furthermore, as Arg32 is conserved in this part of the protein among Gre2p homologs from other fungi (Figure 6), the observations made with Gre2p Arg32Gly,Leu,Asp,Glu underline that conserved amino acids are most often crucial for enzyme function and activity. Thus their sole substitution without changing other parts of an enzyme is likely to result in a mutant enzyme having inferior activity, when compared to its wild-type parent. Consequently further mutations only concerned non- 
conserved amino acids. Thus mutation of Lys36 in Gre2p, which is well conserved (Figure 6) and assumed to be involved in binding the 2'-phosphate group of NADPH (Figure 3), was not considered for mutation.

But in order to decrease the affinity of the enzyme for NADPH a negative charge in this phosphate binding region of Gre2p is a prerequisite. Thus the amino acid upstream of Arg32 (Ala31) was chosen as the next target.

Figure 6. Multiple sequence alignment of proteins homologous to Gre $2 p$ from S. cerevisiae (highlighted in grey; red frame). Conserved amino acids are marked with an asterisk below the alignment, whereas residues thought to be involved in binding NADPH's 2'-phosphate group are indicated by a dot above the alignment. For a full list explaining the abbreviations used see Table 1.

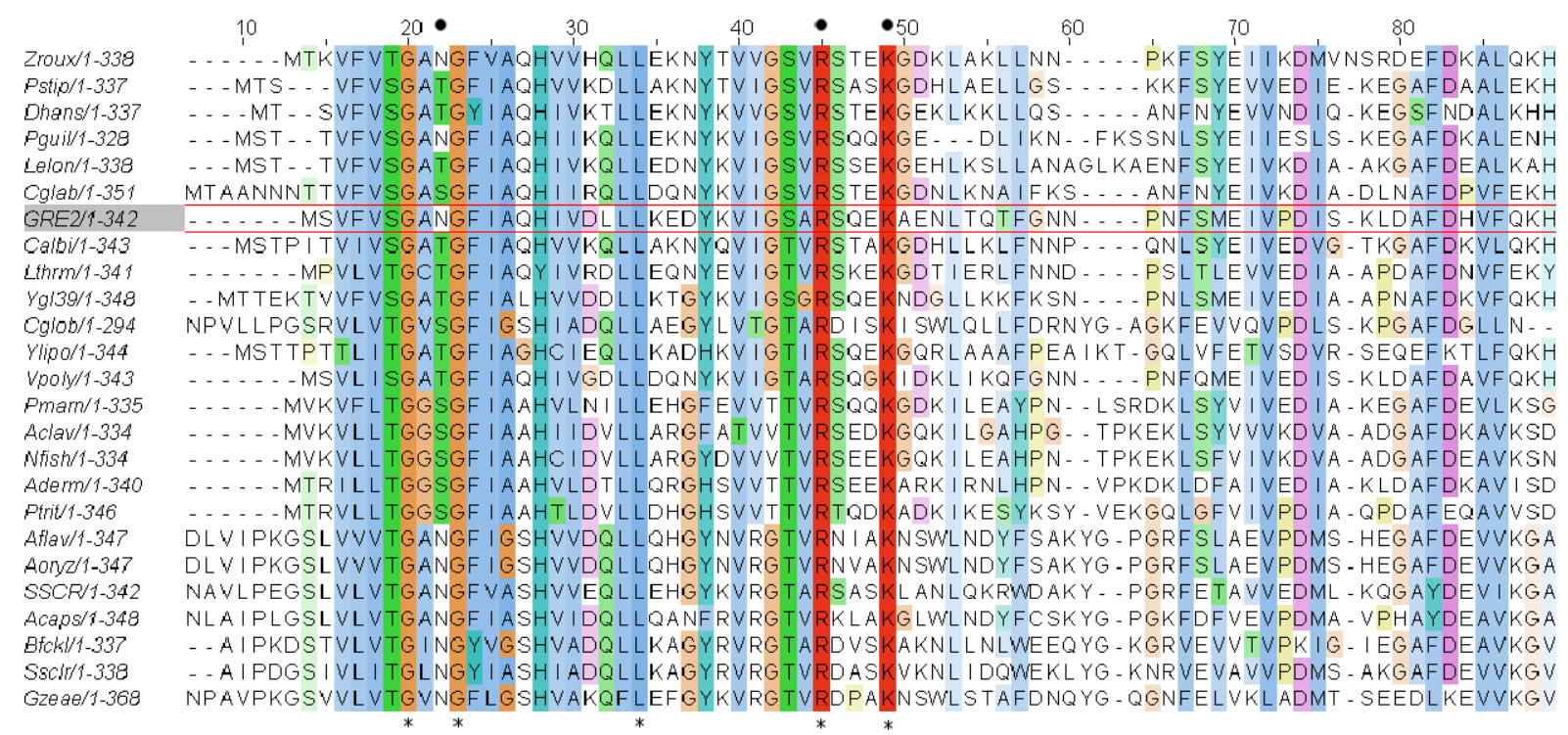

Substituting Ala31 is expected to be successful as this yields an enzyme whose sequence resembles that of the Drosophila alcohol dehydrogenase, an enzyme which is reported to prefer NADH (1B14_A in Figure 7). Introducing an amino acid with an acidic side chain downstream of R32 (S33) is not reasonable, since the resulting enzyme would resemble the structure of the NADPH dependent porcine carbonyl reductase (1N5D_A in Figure 7) and thus is not likely to exhibit a changed cofactor preference.

Although exchanging amino acids equal to Ala31 in Gre2p successfully changed cofactor preference from NADPH to NADH in other SDRs like mouse lung carbonyl reductase [63] and human estrogenic 17- $\beta$-hydroxysteroid dehydrogenase [38], no change in cofactor preference could be observed in Gre2p when Ala31 was replaced by Asp and Glu, respectively. Instead both enzyme variants showed a significant loss of activity regardless of the cofactor used what clearly disqualifies substitution of Ala31 as a strategy for altering cofactor preference in Gre2p. Unfortunately this suggests that mutagenesis strategies are not transferable unrestrictedly from one enzyme to another even if they are homologous and grouped in one family. 
Table 1. Abbreviations used in Figure 6.

\begin{tabular}{|c|c|c|c|}
\hline Abbreviation & $\begin{array}{c}\text { Name/putative function of the } \\
\text { protein }\end{array}$ & Source organism & $\begin{array}{c}\text { NCBI GenBank } \\
\text { Accession number }\end{array}$ \\
\hline Zroux & $\begin{array}{l}\text { AF178079_1 } \\
\text { dehydrogenase }\end{array}$ & Zygosaccharomyces rouxii & AAF22287.1 \\
\hline Pstip & GRE2 methylglyoxal reductase & Pichia stipitis CBS 6054 & XP_001384081 \\
\hline Dhans & $\begin{array}{l}\text { DEHA2A06314p } \\
\text { hypothetical protein }\end{array}$ & Debaryomyces hansenii & CAG84554.2 \\
\hline Pguil & $\begin{array}{l}\text { PGUG_03246 } \\
\text { hypothetical protein }\end{array}$ & Pichia guilliermondii ATCC 6260 & XP_001485517.1 \\
\hline Lelon & hypothetical protein & Lodderomyces elongisporus NRRL YB-4239 & XP_001527072.1 \\
\hline Cglab & hypothetical protein & Candida glabrata & XP_445918.1 \\
\hline GRE2 & $\begin{array}{l}\text { Yol151wp / 3-methyl butanal } \\
\text { reductase }\end{array}$ & Saccharomyces cerevisiae & NP_014490 \\
\hline Calbi & oxidoreductase & Candida albicans SC5314 & XP_719286 \\
\hline Lthrm & KLTH0F04026p & Lachancea thermotolerans CBS6340 & XP_002554383 \\
\hline Ygl39 & dehydrogenase YGL039w & Saccharomyces cerevisiae & NP_011476.1 \\
\hline Cglob & $\begin{array}{l}\text { CHGG_00287 } \\
\text { hypothetical protein }\end{array}$ & Chaetomium globosum CBS 148.51 & XP_001219508.1 \\
\hline Ylipo & YALI0D07062p & Yarrowia lipolytica & XP_502514 \\
\hline Vpoly & hypothetical protein & Vanderwaltozyma polyspora DSM 70294 & XP_001642950.1 \\
\hline Pmarn & ketoreductase & Penicillium marneffei ATCC 18224 & XP_002151938 \\
\hline Aclav & ketoreductase & Aspergillus clavatus NRRL 1 & XP_001275327 \\
\hline Nfish & ketoreductase & Neosartorya fischeri NRRL 181 & XP_001260510 \\
\hline Aderm & ketoreductase & Ajellomyces dermatitidis SLH14081 & XP_002625096 \\
\hline Ptrit & dihydroflavonol-4-reductase & Pyrenophora tritici-repentis Pt-1C-BFP & XP_001938846 \\
\hline Aflav & aldehyd reductase II & Aspergillus flavus NRRL3357 & EED56897.1 \\
\hline Aoryz & RIB40 hypothetical protein & Aspergillus oryzae & XP_001817435.1 \\
\hline SSCR & carbonyl reductase & Sporobolomyces salmonicolor & AAF15999 \\
\hline Acaps & aldehyd reductase & Ajellomyces capsulatus G186AR & EEH09765.1 \\
\hline Bfckl & $\begin{array}{l}\text { BC1G_06734 } \\
\text { hypothetical protein }\end{array}$ & Botryotinia fuckeliana B05.10 & XP_001554946.1 \\
\hline Ssclr & $\begin{array}{l}\text { SS1G_13307 } \\
\text { hypothetical protein }\end{array}$ & Sclerotinia sclerotiorum 1980 & XP_001585790.1 \\
\hline Gzeae & $\begin{array}{l}\text { FG11217.1 } \\
\text { hypothetical protein }\end{array}$ & Gibberella zeae $\mathrm{PH}-1$ & XP_391393.1 \\
\hline
\end{tabular}


Figure 7. Sequence alignment of NADPH and NADH preferring short-chain dehydrogenases / reductases with known crystal structure labeled with its corresponding PDB Code. The N-terminal amino-acid-sequence is shown, which is responsible for cofactor recognition and binding. NADH preferring SDRs are assigned a dot after their respective PDB code (for a full table linking the PDB codes with information on the respective enzyme, see Table 2). Arrows are indicating those amino acids in the $\beta_{2} \alpha_{3}$-turn which according to [49] determine the cofactor preferred by the enzyme.

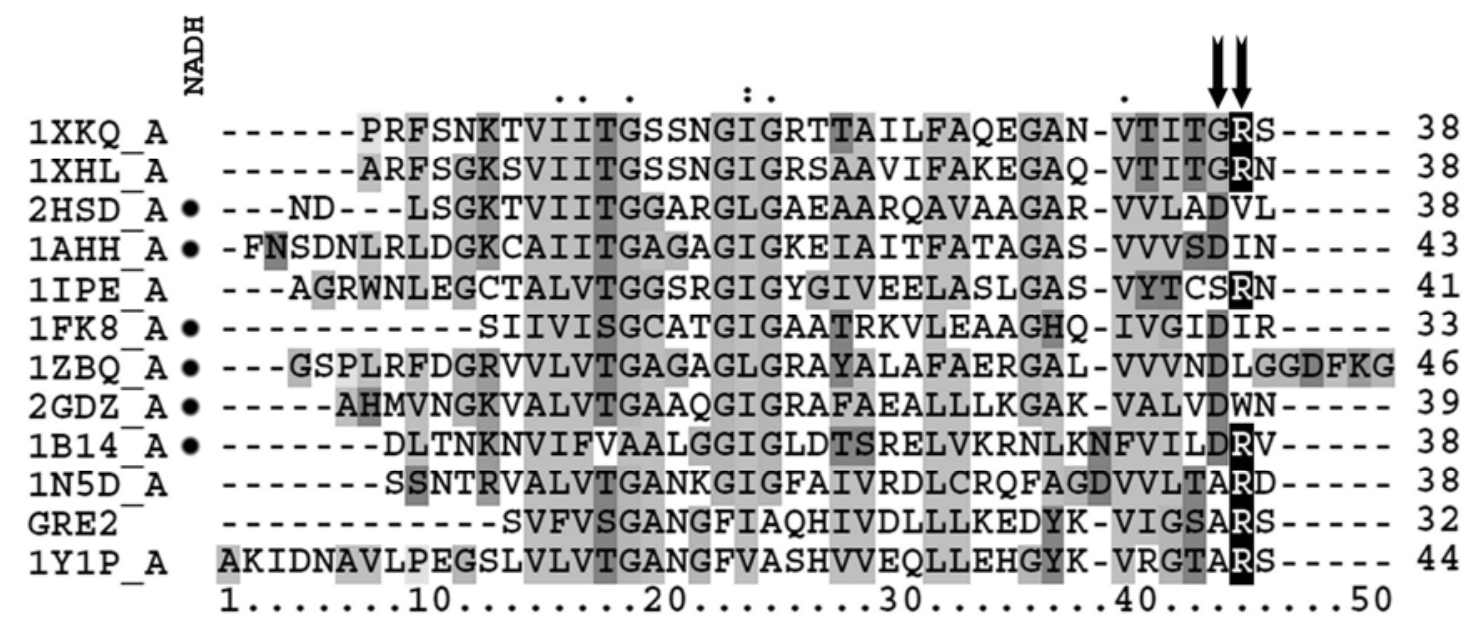

Table 2. Abbreviations used in Figure 7.

\begin{tabular}{|c|c|c|c|}
\hline PDB-Code & Name of the protein & Source organism & Reference \\
\hline 1XKQ & $\begin{array}{l}\text { short-chain dehydrogenase / reductase } \\
\text { with unknown function }\end{array}$ & Caenorhabditis elegans & [74] \\
\hline $1 \mathrm{XHL}$ & tropinone reductase II & Caenorhabditis elegans & [65] \\
\hline 2HSD & $3 \alpha, 20 \beta$-hydroxysteroid dehydrogenase & Streptomyces exfoliates & [75] \\
\hline $1 \mathrm{AHH}$ & $7 \alpha$-hydroxysteroid dehydrogenase & Escherichia coli & [76] \\
\hline 1IPE & tropinone reductase II & Datura stramonium & [77] \\
\hline 1FK8 & $3 \alpha$-hydroxysteroid dehydrogenase & Comamonas testosteroni & [78] \\
\hline 1ZBQ & 17- $\beta$-hydroxysteroid dehydrogenase 4 & Homo sapiens & [79] \\
\hline $2 \mathrm{GDZ}$ & $\begin{array}{l}\text { 15-hydroxyprostaglandin } \\
\text { dehydrogenase type } 1\end{array}$ & Homo sapiens & [80] \\
\hline 1B14 & alcohol dehydrogenase & Drosophila lebanonensis & [81] \\
\hline $1 \mathrm{~N} 5 \mathrm{D}$ & carbonyl reductase & Sus scrofa & [64] \\
\hline
\end{tabular}

One reason for the observed behavior may be the bonding angels $(\Phi / \Psi)$ in Ala31's peptide bond. Assumed that both bonding angels $\Phi / \Psi$ in the homology model of Gre2p match the ones in the template SSCR (PDB: 1Y1P) and remain unchanged after substitution of Ala31 with Glu or Asp, the side chain of the amino acid at position 31 would not point towards the 2'-phosphate group of the cofactors adenine ribose moiety but in the opposite direction (Figure 8). 
Figure 8. Possible orientation of Glu31 in the homology model of Gre2p Ala31Glu (B) compared to the situation in the crystal structure of SSCR (A). In both dehydrogenases the side chain of the amino acid residue upstream of arginine (Ala43 in SSCR; Glu31 in Gre2p Ala31Glu) points away from the cofactors ribosyl 2'-phosphate moiety and is thus not likely to interact with it.
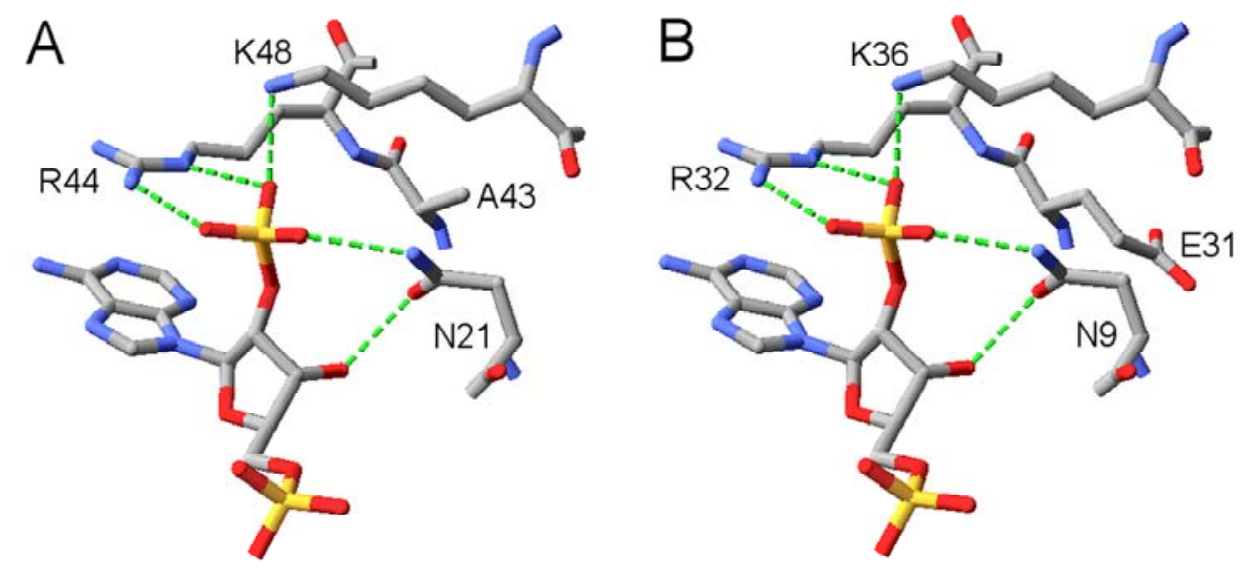

Thus the side chains of neither Glu31 nor Asp31 would be able to adopt a conformation allowing interaction of the side chains carboxy group with the 2'- and 3'-hydroxygroup of the cofactor's adenyl ribose moiety. Instead the side chains would affect other parts of the protein yielding an almost inactive protein. Regardless of the underlying reasons, whose final clarification would require the crystal structure of Gre2p being solved (which is beyond the scope of this contribution) it has to be noted that substitution of Ala31 in Gre2p is unsuitable for generating an NADH dependent variant of the enzyme.

Far better results were obtained by exchanging Asn9 by Asp and Glu, respectively. As is depicted in Figure 5 substitution of Asn9 with Asp brought about a decrease in the NADPH dependent activity while at the same time NADH-dependent 2,5-hexanedione reductase activity increased. This difference becomes even more pronounced if the side chain of the amino acid at position 9 is prolonged by one carbon atom, i.e., substituting Asp9 with Glu.

As Asn9 is already able to interact with the 3'-hydroxy and 2'-phosphate group of the cofactors adenine ribose moiety in the wild-type enzyme, it is reasonable that changing the properties of this amino acids side chain from polar but uncharged (Asn) to charged (Asp, Glu) brings about the electrostatic repulsion needed to decrease binding of NADPH and permits formation of hydrogen bonds between the 2'- and 3'-ribose hydroxyl groups and the side chain carboxyl group (Figure 9).

Compared to Gre2p Asn9Asp formation of hydrogen bonds and repulsion of NADPH's additional phosphate group seems to become more pronounced in Gre2p Asn9Glu (Figure 5). This appears reasonable since the side chain of Glu is one carbon atom longer than the one of Asp and thus brings the carboxy group of Glu9 in closer proximity to the adenylribosyl 2'- and 3'-hydroxygroups, which allows for the establishment of strong hydrogen bonds between Glu9 and the cofactor. Moreover the side chain of Glu9 would even hamper binding of NADPH sterically (Figure 9). 
Figure 9. Proposed binding of NADPH in Gre2p wild-type (A) and its mutant variants Asn9Asp (B) and Asn9Glu (C). In Gre2p Asn9Glu NADH dependent 2,5-hexanedione reductases activity is increased, since Glu9 is able to form hydrogen bonds (green dotted lines) with both of the adenyl ribose hydroxyl groups and constrains binding of NADPH through electrostatic interaction as well as steric hindrance (possible collision with the phosphate moiety is indicated with a purple dotted line).
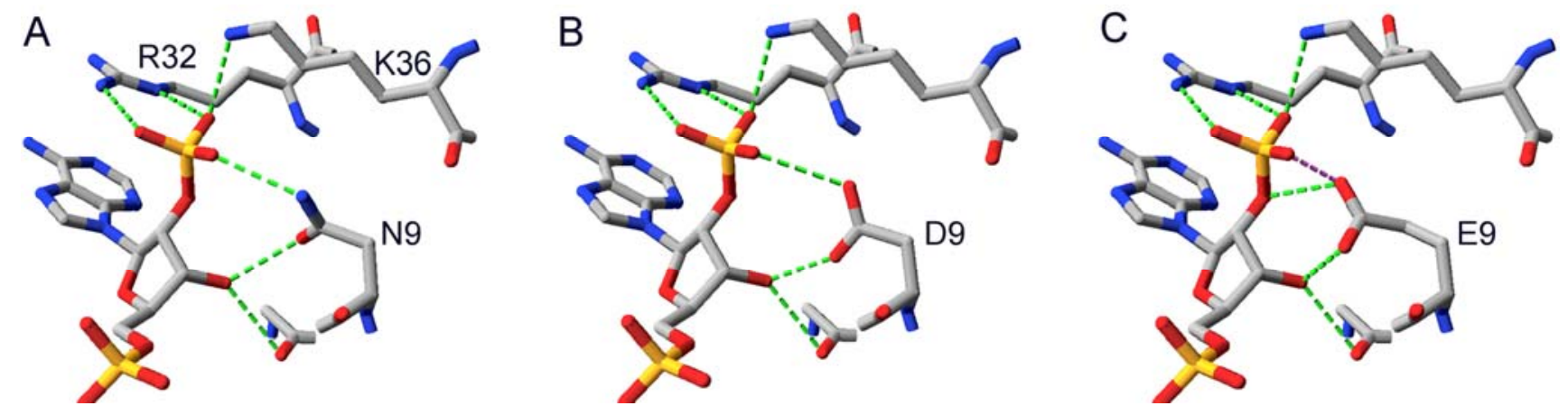

The change of cofactor preference in Gre2p Asn9Glu is further corroborated by kinetic studies of this mutant enzyme. As is shown in Table 3 the mutants apparent Michaelis-constant for NADH is decreased by a factor of 1.5 compared to the wild-type parent. Similarly the apparent maximal velocity of the 2,5-hexanedione reduction using NADH increased almost 2-fold upon exchange of Asn9 with Glu. Thus cofactor preference of Gre2p was changed from strongly preferring NADPH in the wildtype to quite promiscuous in the N9E mutant which has no pronounced preference NADH and NADPH, respectively (Table 3).

As the enzyme is almost as stable as its wild-type parent (the half-live in $0.1 \mathrm{M}$ phosphate buffer $\mathrm{pH}$ 7.0 at $30{ }^{\circ} \mathrm{C}$ was determined to be $24 \mathrm{~h}$ for the wild-type and $21 \mathrm{~h}$ for the Asn9Glu mutant) it may already be used to reduce 2,5-hexandion in vitro using NADH furnishing (5S)-2 and (2S,5S)-1. The stereoselectivity of Gre2p [21,23] is unlikely to be altered by the exchange of Asn9 since the substrate binding pocket is about $15 \AA$ away from Asn9 and made of amino acids far more downstream.

Table 3. Apparent kinetic constants determined for Gre $2 p$ wild-type (Gre $2 p$ wt) and its mutant Gre2p Asn9Glu (Gre2p N9E).

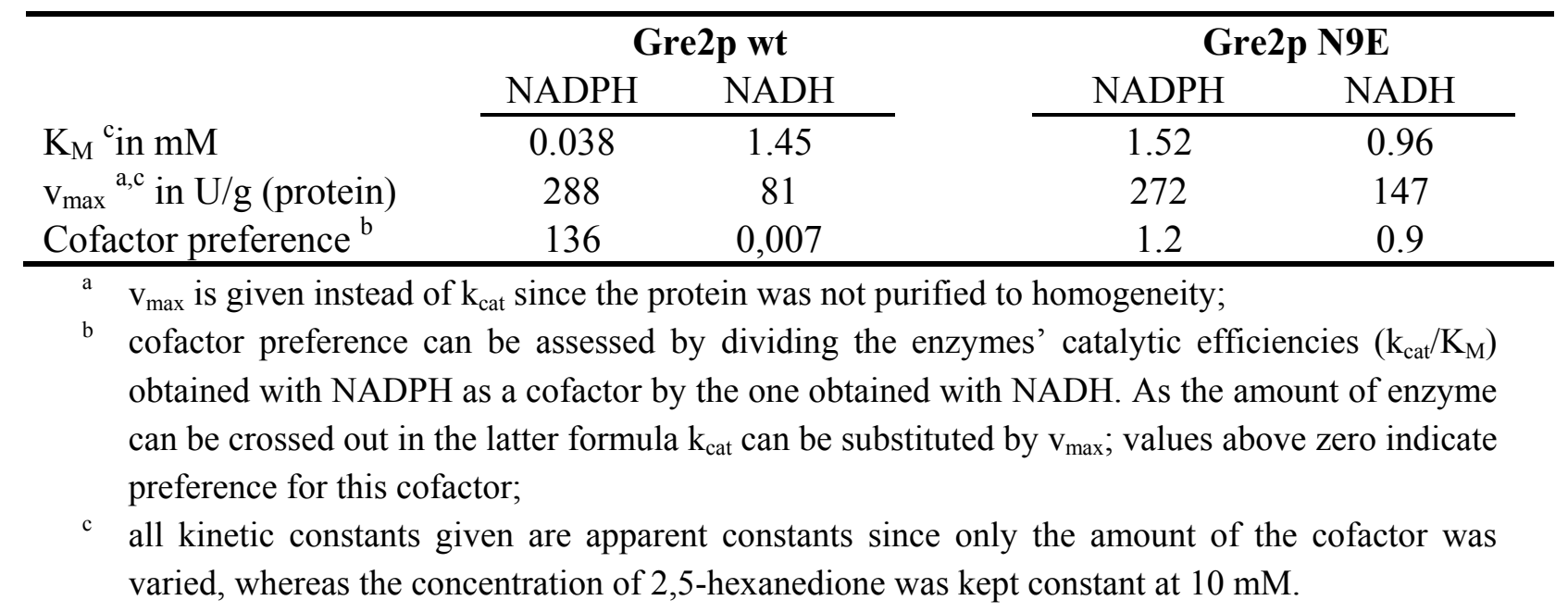


Hence there is substantial evidence that exchanging Asn9, which is situated within the so called "glycine rich motif" of Gre2p, with Asp or Glu improves the enzyme's ability to use NADH as a cofactor. Furthermore this observation appears likely to be not restricted to the single case of Gre $2 p$. Since a hydrophilic amino acid residue (namely Asn, Thr, Ser etc.) corresponding to Asn9 in Gre2p, is found in many NADPH-dependent SDRs (see Figure 6 and [57]), it can be suggested that exchanging Asn9 with Glu and Asp, respectively, will - in most of the cases - result in an improved capability of the enzyme to use NADH as a cofactor. From crystal structures of NADPH-dependent SDRs is furthermore known that this certain amino acid often adopts a conformation which allows formation of hydrogen bonds between this residue and the cofactor's 2'-and 3'-hydroxy groups attached to the adenyl ribose moiety (for a few examples see Figure 10).

Hence exchanging it with Glu and Asp, respectively will most likely lead to an enzyme in which binding of NADH is improved in the same way as is reported for the mutant Gre2p Asn9Glu (Figure 9).

Figure 10. The amino acid residue corresponding to Asn 9 in Gre $2 p$ is a promising target for alteration of cofactor preference in NADPH-dependent SDRs in general, since this amino acid is already forming hydrogen bonds with the 2'-phosphate and 3'-hydroxy group of the cofactor's adenyl ribose moiety. Depicted is the orientation of this certain amino acid towards the 2'-phosphate and 3'-hydroxy group attached to the cofactor's adenyl ribose moiety taken from four representative crystal structure of NADPH dependent SDRs. 1ND5-carbonyl reductase from Sus scrofa [64]; 1XHL-putative tropinone reductase II from Caenorhabditis elegans [65]; 1Y1P-carbonyl reductase from Sporobolomyces salmonicolor [58]; 2C29-dihyroflavonol reductase from Vitis vinifera [66].
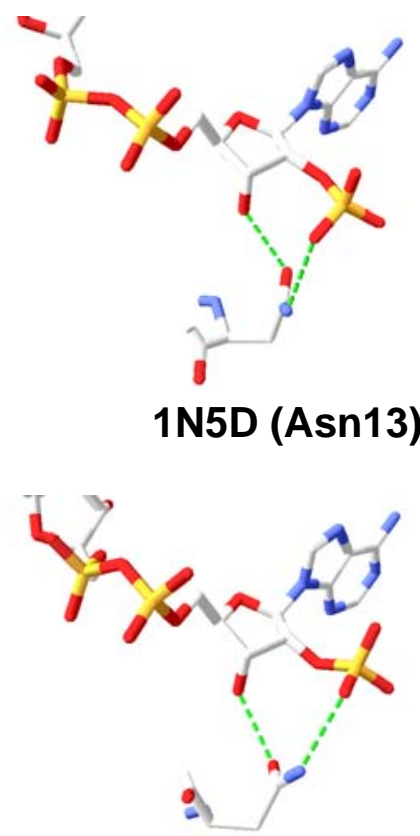

1Y1P (Asn21)

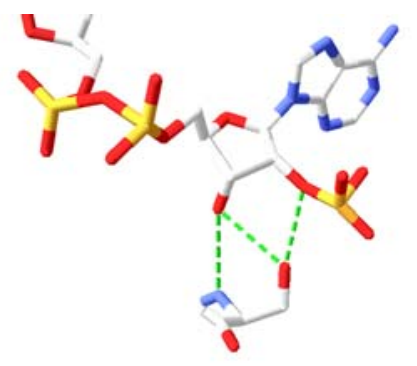

1XHL (Ser15)

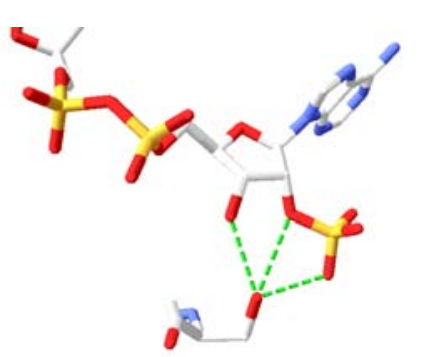

2C29 (Ser14) 
Taken together this study allows concluding that cofactor preference in Gre $2 p$ is not only determined by the presence of an amino acid with basic or acidic side chain in the loop after the $\beta_{2}$-strand. Apparently preference for NADPH is particularly conferred by the presence of a second amino acid with a basic side chain (Arg, Lys) found at least three amino acids downstream of the conserved Arg residue (e.g., in the SDR 2C29 Arg37 is separated from Lys44 by six amino acids).

Thus an inversion of cofactor preference in Gre2p can only be obtained if several amino acids are exchanged. For instance it would be of interest whether an effective enzyme preferring NADH can be obtained through exchanging the full loop after the sheet $\beta 2$ with the one found in $\mathrm{NADH}$ dependent SDRs.

However a single substitution of one amino acid is sufficient to broaden cofactor acceptance and usage. Thus this study has shown that in SDRs amino acids within the conserved GxxG Motif are a valuable target for mutations if cofactor preference is to be altered.

Besides the success of having generated a Gre2p mutant with relaxed cofactor preference it must be noted that this mutant enzyme does not reach the ideal of being as catalytically efficient using NADH as it is the wild-type using NADPH. As such the mutant enzymes $\mathrm{K}_{\mathrm{M}}(\mathrm{NADH})$ is still more than 20 times higher than the $\mathrm{K}_{\mathrm{M}}(\mathrm{NADPH})$ of the wild-type Gre $2 \mathrm{p}$ and the ratio $\mathrm{v}_{\max }(\mathrm{NADPH})_{\mathrm{wt}} / \mathrm{v}_{\max }(\mathrm{NADH})_{\mathrm{N} 9 \mathrm{E}}$ is significantly greater than one, although the ultimate goal would be to keep this ratio at a value of one or below.

Similar observations were also made in previous rational mutagenesis studies aiming for alteration of cofactor preference in short-chain dehydrogenases [38,47,48]. For instance Huang et al., inverted the cofactor preference of human estrogenic 17- $\beta$-hydroxysteroid dehydrogenase by replacing Leu36 with Asp (Leu36 corresponds to Ala31 in Gre2p). But also in this case the mutant is not as catalytically efficient as the parent (30 times smaller catalytic efficiency), which is also reflected in the reported Michaelis-constants. As such the mutants (L36D) $\mathrm{K}_{\mathrm{M}}(\mathrm{NADH})$ is 17 times bigger than the $\mathrm{K}_{\mathrm{M}}(\mathrm{NADPH})$ of the corresponding wild-type enzyme [38].

Thus it appears that although a switch or at least a relaxation in cofactor preference of a short-chain dehydrogenase is achievable by merely mutating one single amino acid residue, the resulting enzyme will most probably not have the same catalytic efficiency as its wild-type parent. This result is rather disadvantageous if the enzyme of choice is to be used in a biotechnological process. Since high space time yields $(\sim 100 \mathrm{~g} / \mathrm{L} * \mathrm{~d})$ and low biocatalyst loading are clear prerequisites for economically viable biotransformations [67], mutagenesis is expected to provide enzymes which exhibit the desired properties, with a catalytic efficiency being equal to or preferentially exceeding that of their wild-type counterparts. In order to achieve this by rational approaches, far too less is known about enzyme architecture and structure activity relationships in whole enzymes. Thus from a current point of view methods using random mutagenesis and high-throughput screening appear more promising than rational approaches in generating new powerful tailored biocatalysts. However with an increasing knowledge in enzyme architecture and structure activity relationship rational design of tailor made enzymes appears not only feasible but also much less time-consuming than multiple rounds of diversity generation and successive screening. 


\section{Experimental Section}

\subsection{Chemicals}

Technical grade 2,5-hexanedione was obtained from Wacker Chemie AG (Munich, Germany) and purified to $>99 \%$ by distillation. DNA-modifying enzymes were purchased from Fermentas (St. LeonRot, Germany).

\subsubsection{Strains and Growth Conditions}

Within this study plasmid propagation was carried out with Escherichia coli TOP10 (Invitrogen $^{\text {TM }}$, Calrlsbad, CA, USA), whereas E. coli BL21 (DE3) pLysS (Invitrogen ${ }^{\mathrm{TM}}$ ) was used for production of recombinant proteins. All strains generated were stored at $-80{ }^{\circ} \mathrm{C}$ as glycerol stocks $(15 \%$ glycerol in LB-medium). Cultivation of E. coli strains was carried out at $37{ }^{\circ} \mathrm{C}$ in LB (lysogeny broth)-medium ( $1 \%$ bacto-tryptone; $0.5 \%$ yeast extract; $1 \% \mathrm{NaCl} ; \mathrm{pH} 7.5)$ containing the appropriate antibiotics (E. coli TOP10 strains: $100 \mu \mathrm{g} / \mathrm{mL}$ ampicillin; E. coli BL21 strains: $100 \mu \mathrm{g} / \mathrm{mL}$ ampicillin $+35 \mu \mathrm{g} / \mathrm{mL}$ chloramphenicol). Medium was solidified with $1.8 \%$ agar agar when needed.

In order to produce plasmid encoded proteins in E.coli BL21(DE3) pLysS, fresh LB-medium was inoculated with pre-grown (LB-media; $37{ }^{\circ} \mathrm{C}$, overnight) cells yielding an $\mathrm{OD}_{620}$ of 0.2. The growth of the culture at $30^{\circ} \mathrm{C}$ was monitored until the $\mathrm{OD}_{620}$ had reached 0.7 . At this point IPTG was added up to a final concentration of $1 \mathrm{mM}$. The cultivation was continued for another $3 \mathrm{~h}$ before the cells were harvested by centrifugation $(3,220 \times \mathrm{g} ; 10 \mathrm{~min}$ ), washed (with water and with $0.1 \mathrm{M}$ potassium phosphate buffer) and subjected to disintegration.

\subsubsection{Molecular Biology Techniques/Construction of Plasmids}

Cloning and modification of DNA was carried out using standard techniques as described by [68]. Plasmids were isolated using the GeneJet MiniPrep Kit from Fermentas. In order to construct an E. coli strain capable of Gre2p expression, the GRE2 gene was subcloned from p423-GPD-YOL151w (HIS3) [69] into pRSET B (Invitrogen) after introducing the restriction sites PstI and HindIII. The resulting plasmid was named pRSET B GRE2.Site-directed mutations were introduced into the gene of interest by using an adapted Quikchange ${ }^{\mathrm{TM}}$ protocol. Therefore a $50 \mu \mathrm{L}$ PCR-reaction contained $0.5 \mu \mathrm{g}$ of template (pRSET B GRE2), $200 \mu \mathrm{M}$ dNTP's, $0.18 \mu \mathrm{M}$ of each primer (Table 4) and 2.5 U PwoPolymerase (Roche). After a $5 \mathrm{~min}$ initiation phase at $94{ }^{\circ} \mathrm{C}$ to denature template DNA, amplification of the desired plasmid was achieved with 18 cycles of the following temperature regime: $94{ }^{\circ} \mathrm{C}$ $(0.5 \mathrm{~min}) ; 55{ }^{\circ} \mathrm{C}(0.5 \mathrm{~min}) ; 68{ }^{\circ} \mathrm{C}(6 \mathrm{~min})$ followed by a final $10 \mathrm{~min}$ elongation phase at $68{ }^{\circ} \mathrm{C}$. The success of the PCR could be verified by agarose-gel electrophoresis of $15 \mu \mathrm{L}$ of the product mixture. In order to destroy the template $20 \mu \mathrm{L}$ of PCR product were treated with $1 \mu \mathrm{L}$ of DpnI FastDigest ${ }^{\mathrm{TM}}$ (Fermentas) enzyme for $1 \mathrm{~h}$ at $37^{\circ} \mathrm{C}$. Finally $1 \mu \mathrm{L}$ of the DpnI treated and untreated PCR-reactionproduct, respectively was transformed into electrocompetent E.coli TOP10 cells by electroporation. After cultivation on LB-agar overnight 2 colonies were picked for propagation, isolation and sequencing of the plasmid if the number of colonies arising form cells transformed with untreated 
PCR-product exceeded the number of colonies arising from cells transformed with DpnI treated PCR-product, by a factor of $\sim 10$.

Table 4. Primers used in this study.

\begin{tabular}{|c|c|}
\hline Name $^{a}$ & Sequence $^{b}$ \\
\hline GRE2N_F (PstI) ${ }^{\mathrm{c}}$ & $5^{\prime \prime}$ - AACTGCAGAACAGATAGCAGTATCACACGCCCGTAAAT - $3^{\prime}$ \\
\hline GRE2N_R (HindIII) ${ }^{\mathrm{c}}$ & $5^{\prime}$ - AAAAGCTTGAAGAGAAAAATGCGCAGAGATGTACTAGATGAT- $3^{\prime}$ \\
\hline R32E_F & 5' - GGTCATCGGTTCTGCCGAAAGTCAAGAAAAGGCCGAGAATTTAACGG - 3' \\
\hline R32D_F & 5' - GGTCATCGGTTCTGCCGACAGTCAAGAAAAGGCCGAGAATTTAACGG - 3' \\
\hline R32G_F (BamHI) & 5' - GGTCATCGGTTCTGCCGGATCCCAAGAAAAGGCCGAGAATTTAACGG - 3' \\
\hline R32L_F & 5' - GGTCATCGGTTCTGCTTTAAGTCAAGAAAAGGCCGAGAATTTAACGC - 3' \\
\hline A31E_F & $5^{\prime}$ - GAAGACTATAAGGTCATCGGTTCTGAGAGAAGTCAAGAAAAGGCC - $3^{\prime}$ \\
\hline A31D_F (BstYI) & $5^{\prime}$ - GAAGACTATAAGGTCATCGGATCTGATAGAAGTCAAGAAAAGGCC - $3^{\prime}$ \\
\hline N9D_F (BsgI) & 5' - CAGTTTTTGTTTCAGGTGCAGACGGGTTCATTGCCCAAC - $3^{\prime}$ \\
\hline N9E_F & 5' - CAGTTTTTGTTTCAGGTGCTGAGGGGTTCATTGCCCAAC - $3^{\prime}$ \\
\hline
\end{tabular}

a name of the primer is deduced from the amino acids changed in Gre2p; only forward primer given; reverse primer corresponds to the reverse complement of the forward primer;

b nucleotides in the primer being responsible for amino acid exchange in Gre2p are printed in bold face; restriction sites are underlined; $\mathbf{c}$ - Primer for introduction of restriction sites (given in parenthesis; underlined in sequence) flanking the cloned GRE2 gene.

\subsection{Homology Modeling}

The three-dimensional structural model of Gre $2 p$ was constructed through homology modeling using the crystal structure of carbonyl reductase from Sporobolomyces salmonicolor (PDB: 1Y1P) as a template. In brief a sequence alignment between GRE2 and 1Y1P was generated under due consideration of the templates secondary structure with Clustal X2 (profile alignment mode, standard parameters) [70]. The alignment was optimized manually by using the software swiss pdb-viewer (SPDV) [71] Version 4.0.1, with the "mean force potential" [72] of each amino acids serving as the optimization criteria. After removal of clashes in the protein structure by SPDV, the final homology model was automatically built by the Swiss Model Server [73]. The latter also allows for assessing the quality of the obtained model through different scoring functions such as QMEAN [54] and ProQres [53]. All figures showing enzyme structures were generated with SPDV Version 4.0.1 [71].

\subsubsection{Enzyme Assays}

The activity of Gre2p towards the diketone 2,5-hexanedione was determined by measuring the decrease in absorbance of $\mathrm{NAD}(\mathrm{P}) \mathrm{H}$ at $340 \mathrm{~nm}$ with a spectrophotometer. If not stated otherwise, the standard assay in 0.1 sodium phosphate buffer $\mathrm{pH} 7.0$ contained, the enzyme, $10 \mathrm{mM}$ 2,5-hexanedione and $0.2 \mathrm{mM}$ of the reduced cofactor. The reaction was started by addition of 2,5-hexanedione and monitored for $90 \mathrm{~s}$. In terms of this assay $1 \mathrm{U}$ corresponds to the formation and consumption, respectively of $1 \mu \mathrm{mol}$ of cofactor per min at $\mathrm{pH} 7.0$ and $30{ }^{\circ} \mathrm{C}$. 


\subsubsection{Disintegration of $E$. coli Cells}

E. coli cells were disintegrated by adding the non-ionic detergent B-PER (Pierce) in twice the amount of the cells wet weight. After addition of DNAse (Promega; $1 \mathrm{U} / \mu \mathrm{L} ; \mathrm{v}_{\mathrm{DNAse}}=1 / 60$ of the volume of B-PER) the mixture was shaken for $20 \mathrm{~min}$. The cell crude extract was obtained after removing cell debris by centrifugation $(10 \mathrm{~min} ; 16,100 \times \mathrm{g})$.

\subsubsection{Kinetic Characterization}

Determination of an enzymes apparent Michaelis-constant $\mathrm{K}_{\mathrm{M}}$ and the apparent maximal velocity $\mathrm{v}_{\max }$ for the reduction of 2,5-hexanedione was carried out by using 2,5-hexanedione in saturation $(10 \mathrm{mM})$ and varying the concentration of the cofactor within the range of $0.1-4 \mathrm{mmol}$. The constants were obtained through fitting the data to the Michaelis-Menten-equation (non-linear regression). Before use the recombinant enzyme was enriched from crude extracts of E. coli by treating the crude extract with $20 \%\left(\mathrm{NH}_{4}\right)_{2} \mathrm{SO}_{4}$ and removing the precipitate.

\section{Conclusions}

It is widely recognized that biocatalysis is an invaluable tool to produce chiral building blocks and other high value chemicals in an economically attractive and environmentally benign way. However in order to be applied in an industrially relevant process on a larger scale, biocatalysts often need to be tailored to the process requirements. One example is switching the cofactor preference of NADPH dependent dehydrogenases to $\mathrm{NADH}$, the latter being more cost-effective and more stable than its phosphorylated counterpart. The method of choice to achieve this goal is mutagenesis, as it allows for tailoring the enzyme's properties through either random or rational modification of its primary structure.

In this study we investigated the impact of rationally introduced mutations upon cofactor preference of the NADPH-preferring dehydrogenase Gre2p originating from S. cerevisiae, which proved to be a valuable biocatalyst such as the reduction of the diketone 2,5-hexanedione. As the products of this reaction [(5S)-hydroxy-2-hexanone and (2S,5S)-hexanediol] are important chiral building-blocks, Gre $2 p$ is of major economic relevance for industry. However in order to apply this process on an industrial scale, an NADH preferring variant of Gre2p would be favorable.

In theory substitution of one amino acid should suffice to invert cofactor preference. Although this has been reported to be true for a series of short-chain-dehydrogenases - an enzyme superfamily Gre2p belongs to - the situation appears more complex with this enzyme. However there were two promising enzyme variants among the set of mutants generated and tested for activity which lead to a relaxation of cofactor preference yielding a mutant which accepts NADPH as well as NADH for the reduction of 2,5-hexanedione. The obtained results suggest that the GxxG motif which is often found at the N-termini of short-chain dehydrogenases/reductases (SDR), is a promising target in general, if the cofactor preference of a SDR is to be altered. As the impact of introduced mutations on enzyme activity and selectivity is still not predictable reliably, more structure activity studies on enzymes are needed in order to achieve the ultimate goal of de novo design of tailored biocatalysts. 


\section{Acknowledgements}

We gratefully acknowledge financial support by Deutsche Bundesstiftung Umwelt (Contract \#13138-32) and the European Union within the FP6 funded NoE BioSim (Contract \#LSHB-CT-2004005137). The authors wish to thank K.-H. van Pée and B. Hahn-Hägerdahl for helpful discussions and support.

\section{References}

1. Bhowmick, K.; Joshi, N. Syntheses and applications of C2-symmetric chiral diols. Tetrahedron: Asymmetry 2006, 17, 1901-1929.

2. Bode, S.; Wolberg, M.; Müller, M. Stereoselective synthesis of 1,3-diols. Synthesis 2006, 4, 557-588.

3. Burk, M.J. Modular phospholane ligands in asymmetric catalysis. Acc. Chem. Res. 2000, 33, 363-372.

4. Burk, M.J.; Feaster, J.E.; Harlow, R.L. New chiral phospholanes; synthesis, characterization, and use in asymmetric hydrogenation reactions. Tetrahedron: Asymmetry 1991, 2, 569-592.

5. Burk, M.; Ramsden, J. Modular, chiral P-heterocycles in asymmetric catalysis. In Handbook of Chiral Chemicals; Ager, D., Ed.; CRC Press: Boca Raton, FL, USA, 2006; pp. 249-268.

6. Short, R.P.; Kennedy, R.M.; Masamune, S. An improved synthesis of (-)-(2R,5R)-2,5dimethylpyrrolidine. J. Org. Chem. 1989, 54, 1755-1756.

7. Díez, E.; Fernández, R.; Marqués-López, E.; Martín-Zamora, E.; Lassaletta, J.M. Asymmetric synthesis of trans-3-amino-4-alkylazetidin-2-ones from chiral N,N-dialkylhydrazones. Org. Lett. 2004, 6, 2749-2752.

8. Cowart, M.; Pratt, J.; Stewart, A.; Bennani, Y.; Esbenshade, T.; Hancock, A. A new class of potent non-imidazole H3 antagonists: 2-aminoethylbenzofurans. Bioorg. Med. Chem. Lett. 2004, 14, 689-693.

9. Depré, D.; Chen, L.Y.; Ghosez, L. A short multigram asymmetric synthesis of prostanoid scaffolds. Tetrahedron 2003, 59, 6797-6812.

10. Fan, Q.H.; Yeung, C.H.; Chan, A.S.C. An improved synthesis of chiral diols via the asymmetric catalytic hydrogenation of prochiral diones. Tetrahedron: Asymmetry 1997, 8, 4041-4045.

11. Solladie, G.; Huser, N.; Garcia-Ruano, J.L.; Adrio, J.; Carreno, M.C.; Tito, A. Asymmetric synthesis of both enantiomers of 2.5-hexane diol and 2.6- heptane diol induced by chiral sulfoxides. Tetrahedron Lett. 1994, 35, 5297-5300.

12. Bach, J.; Berenguer, R.; Garcia, J.; Loscertales, T.; Manzanal, J.; Vilarrasa, J. Stereoselective reduction of unsaturated 1,4-diketones. A practical route to chiral 1,4-diols. Tetrahedron Lett. 1997, 38, 1091-1094.

13. Mattson, A.; Ohrner, N.; Hult, K.; Norin, T. Resolution of diols with C2-symmetry by lipase catalysed transesterification. Tetrahedron: Asymmetry 1993, 4, 925-930.

14. Nagai, H.; Morimoto, T.; Achiwa, K. Facile enzymatic synthesis of optically active 2,5hexanediol derivatives and its application to the preparation of optically pure cyclic sulfate for chiral ligands. Synlett 1994, 4, 289-290. 
15. Trost, B.M. Atom economy - A challenge for organic synthesis: Homogeneous catalysis leads the way. Angew. Chem. Int. Edt. 1995, 34, 259-281.

16. Sheldon, R.; van Rantwijk, F. Biocatalysis for sustainable organic synthesis. Aust. J. Chem. 2004, 57, 281-289.

17. Alcalde, M.; Ferrer, M.; Plou, F.; Ballesteros, A. Environmental biocatalysis: from remediation with enzymes to novel green processes. Trends Biotechnol. 2006, 24, 281-287.

18. Lieser, J.K. A simple synthesis of (S,S)-2,5-hexanediol. Synth. Commun. 1983, 13, 765-767.

19. Daussmann, T.; Hennemann, H.G.; Rosen, T.C.; Dünkelmann, P. Enzymatic technologies for the synthesis of chiral alcohol derivatives. Chem. Ing. Technol. 2006, 78, 249-255.

20. Goldberg, K.; Edegger, K.; Kroutil, W.; Liese, A. Overcoming the thermodynamic limitation in asymmetric hydrogen transfer reactions catalyzed by whole cells. Biotechnol. Bioeng. 2006, 95, 192-198.

21. Müller, M.; Katzberg, M.; Bertau, M.; Hummel, W. Highly efficient and stereoselective biosynthesis of (2S,5S)-hexanediol with a dehydrogenase from Saccharomyces cerevisiae. Org. Biomol. Chem. 2010, 8, 1540-1550.

22. Watanabe, S.; Mitsuhashi, S.; Kumobayashi, H. Process for producing optically active gammahydroxyketones. European Patent EP 0592881B1, 1998.

23. Katzberg, M.; Wechler, K.; Müller, M.; Dunkelmann, P.; Stohrer, J.; Hummel, W.; Bertau, M. Biocatalytical production of (5S)-hydroxy-2-hexanone. Org. Biomol. Chem. 2009, 7, 304-314.

24. Edegger, K.; Mang, H.; Faber, K.; Gross, J.; Kroutil, W. Biocatalytic oxidation of sec-alcohols via hydrogen transfer. J. Mol. Catal. A 2006, 251, 66-70.

25. Ema, T.; Moriya, H.; Kofukuda, T.; Ishida, T.; Maehara, K.; Utaka, M.; Sakai, T. High enantioselectivity and broad substrate specificity of a carbonyl reductase: Towards a versatile biocatalyst. J. Org. Chem. 2001, 66, 8682-8684.

26. Ema, T.; Yagasaki, H.; Okita, N.; Nishikawa, K.; Korenaga, T.; Sakai, T. Asymmetric reduction of a variety of ketones with a recombinant carbonyl reductase: Identification of the gene encoding a versatile biocatalyst. Tetrahedron: Asymmetry 2005, 16, 1075-1078.

27. Kaluzna, I.; Andrew, A.A.; Bonilla, M.; Martzen, M.R.; Stewart, J.D. Enantioselective reductions of ethyl 2-oxo-4-phenylbutyrate by Saccharomyces cerevisiae dehydrogenases. J. Mol. Catal. B 2002, 17, 101-105.

28. Katz, M.; Hahn-Hägerdal, B.; Gorwa-Grauslund, M.F. Screening of two complementary collections of Saccharomyces cerevisiae to identify enzymes involved in stereo-selective reductions of specific carbonyl compounds: An alternative to protein purification. Enzyme Microb. Technol. 2003, 33, 163-172.

29. Kaluzna, I.A.; Matsuda, T.; Sewell, A.K.; Stewart, J.D. Systematic investigation of Saccharomyces cerevisiae enzymes catalyzing carbonyl reductions. J. Am. Chem. Soc. 2004, 126, 12827-12832.

30. Johanson, T.; Katz, M.; Gorwa-Grauslund, M.F. Strain engineering for stereoselective bioreduction of dicarbonyl compounds by yeast reductases. FEMS Yeast Res. 2005, 5, 513-525.

31. Kaluzna, I.A.; Feske, B.D.; Wittayanan, W.; Ghiviriga, I.; Stewart, J.D. Stereoselective, biocatalytic reductions of $\alpha$-Chloro- $\beta$-keto esters. J. Org. Chem. 2005, 70, 342-345. 
32. Ema, T.; Yagasaki, H.; Okita, N.; Takeda, M.; Sakai, T. Asymmetric reduction of ketones using recombinant E. coli cells that produce a versatile carbonyl reductase with high enantioselectivity and broad substrate specificity. Tetrahedron 2006, 62, 6143-6149.

33. Warringer, J.; Blomberg, A. Involvement of yeast YOL151W/GRE2 in ergosterol metabolism. Yeast 2006, 23, 389-398.

34. Hauser, M.; Horn, P.; Tournu, H.; Hauser, N.C.; Hoheisel, J.D.; Brown, A.J.P.; Dickinson, J.R. A transcriptome analysis of isoamyl alcohol-induced filamentation in yeast reveals a novel role for Gre2p as isovaleraldehyde reductase. FEMS Yeast Res. 2007, 7, 84-92.

35. Chen, C.N.; Porubleva, L.; Shearer, G.; Svrakic, M.; Holden, L.G.; Dover, J.L.; Johnston, M.; Chitnis, P.R.; Kohl, D.H. Associating protein activities with their genes: rapid identification of a gene encoding a methylglyoxal reductase in the yeast Saccharomyces cerevisiae. Yeast 2003, 20, 545-554.

36. Wu, J.; Wu, L.; Knight, J. Stability of NADPH: Effect of various factors on the kinetics of degradation. Clin. Chem. 1986, 32, 314-319.

37. Andreadeli, A.; Platis, D.; Tishkov, V.; Popov, V.; Labrou, N.E. Structure-guided alteration of coenzyme specificity of formate dehydrogenase by saturation mutagenesis to enable efficient utilization of NADP ${ }^{+}$. FEBS J. 2008, 275, 3859-3869.

38. Huang, Y.W.; Pineau, I.; Chang, H.J.; Azzi, A.; Bellemare, V.; Laberge, S.; Lin, S.X. Critical residues for the specificity of cofactors and substrates in human estrogenic 17ß-hydroxysteroid dehydrogenase 1: Variants designed from the three-dimensional structure of the enzyme. Mol. Endocrinol. 2001, 15, 2010-2020.

39. Serov, A.E.; Popova, A.S.; Fedorchuk, V.V.; Tishkov, V.I. Engineering of coenzyme specificity of formate dehydrogenase from Saccharomyces cerevisiae. Biochem. J. 2002, 367, 841-847.

40. Steen, I.; Lien, T.; Madsen, M.; Birkeland, N.K. Identification of cofactor discrimination sites in NAD-isocitrate dehydrogenase from Pyrococcus furiosus. Arch. Microbiol. 2002, 178, 297-300.

41. Kristan, K.; Stojan, J.; Moller, G.; Adamski, J.; Rizner, T.L. Coenzyme specificity in fungal 17 beta-hydroxysteroid dehydrogenase. Mol. Cell. Endocrinol. 2005, 241, 80-87.

42. Rosell, A.; Valencia, E.; Ochoa, W.F.; Fita, I.; Pares, X.; Farres, J. Complete reversal of coenzyme specificity by concerted mutation of three consecutive residues in alcohol dehydrogenase. J. Biol. Chem. 2003, 278, 40573-40580.

43. Ehrensberger, A.H.; Elling, R.A.; Wilson, D.K. Structure-guided engineering of xylitol dehydrogenase cosubstrate specificity. Structure 2006, 14, 567-575.

44. Bubner, P.; Klimacek, M.; Nidetzky, B. Structure-guided engineering of the coenzyme specificity of Pseudomonas fluorescens mannitol 2-dehydrogenase to enable efficient utilization of NAD(H) and NADP(H). Febs Lett. 2008, 582, 233-237.

45. Jörnvall, H.; Persson, B.; Krook, M.; Atrian, S.; Gonzàlez-Duarte, R.; Jeffery, J.; Ghosh, D. Shortchain dehydrogenases/reductases (SDR). Biochemistry 1995, 34, 6003-6013.

46. Stewart, J.D.; Rodriguez, S.; Kayser, M.M. Cloning, structure and activity of ketone reductases from baker's yeast. In Enzyme Technologies for Pharmaceutical and Biotechnological Applications; Marcel Dekker: New York, NY, USA, 2001; Chapter 7, pp. 175-207. 
47. Schlieben, N.H.; Niefind, K.; Müller, J.; Riebel, B.; Hummel, W.; Schomburg, D. Atomic resolution structures of R-specific alcohol dehydrogenase from Lactobacillus brevis provide the structural bases of its substrate and cosubstrate specificity. J. Mol. Biol. 2005, 349, 801-813.

48. Nakanishi, M.; Matsuura, K.; Kaibe, H.; Tanaka, N.; Nonaka, T.; Mitsui, Y.; Hara, A. Switch of coenzyme specificity of mouse lung carbonyl reductase by substitution of threonine 38 with aspartic acid. J. Biol. Chem. 1997, 272, 2218-2222.

49. Duax, W.L.; Pletnev, V.; Addlagatta, A.; Bruenn, J.; Weeks, C.M. Rational proteomics I. Fingerprint identification and cofactor specificity in the short-chain oxidoreductase (SCOR) enzyme family. Proteins 2003, 53, 931-943.

50. Otten, L.G.; Hollmann, F.; Arends, I.W. Enzyme engineering for enantioselectivity: From trialand-error to rational design? Trends Biotechnol. 2010, 28, 46-54.

51. Rost, B. Twilight zone of protein sequence alignments. Protein Eng. Design Select 1999, 12, $85-94$.

52. Chothia, C.; Lesk, A.M. The relation between the divergence of sequence and structure in proteins. EMBO J. 1986, 5, 823-826.

53. Wallner, B.; Elofsson, A. Identification of correct regions in protein models using structural, alignment, and consensus information. Protein Sci. 2006, 15, 900-913.

54. Benkert, P.; Tosatto, S.C.E.; Schomburg, D. QMEAN: A comprehensive scoring function for model quality assessment. Proteins 2008, 71, 261-277.

55. Rossmann, M.G.; Moras, D.; Olsen, K.W. Chemical and biological evolution of a nucleotidebinding protein. Nature 1974, 250, 194-199.

56. Kallberg, Y.; Oppermann, U.; Jornvall, H.; Persson, B. Short-chain dehydrogenase. Protein Sci. 2002, 11, 636-641.

57. Kavanagh, K.; Jornvall, H.; Persson, B.; Oppermann, U. The SDR superfamily: functional and structural diversity within a family of metabolic and regulatory enzymes. Cell. Mol. Life Sci. 2008, 65, 3895-3906.

58. Kamitori, S.; Iguchi, A.; Ohtaki, A.; Yamada, M.; Kita, K. X-ray structures of NADPH-dependent carbonyl reductase from Sporobolomyces salmonicolor provide insights into stereoselective reductions of carbonyl compounds. J. Mol. Biol. 2005, 352, 551-558.

59. Jörnvall, H.; Persson, M.; Jeffery, J. Alcohol and polyol dehydrogenases are both divided into two protein types, and structural properties cross-relate the different enzyme activities within each type. Proc. Natl. Acad. Sci. USA 1981, 78, 4226-4230.

60. Geissler, R.; Brandt, W.; Ziegler, J. Molecular modeling and site-directed mutagenesis reveal the benzylisoquinoline binding site of the short-chain dehydrogenase/reductase salutaridine reductase. Plant Physiol. 2007, 143, 1493-1503.

61. McKeever, B.M.; Hawkins, B.K.; Geissler, W.M.; Wu, L.; Sheridan, R.P.; Mosley, R.T.; Andersson, S. Amino acid substitution of arginine 80 in 17ß-hydroxysteroid dehydrogenase type 3 and its effect on NADPH cofactor binding and oxidation/reduction kinetics. Biochim. Biophys. Acta 2002, 1601, 29-37.

62. Crowley, P.B.; Golovin, A. Cation-Pi interactions in protein-protein interfaces. Proteins 2005, 59, 231-239. 
63. Nakanishi, M.; Kaibe, H.; Matsuura, K.; Kakumoto, M.; Tanaka, N.; Nonaka, T.; Mitsui, Y.; Hara, A. Site-directed mutagenesis of residues in coenzyme-binding domain and active site of mouse lung carbonyl reductase. Adv. Exp. Med. Biol. 1997, 414, 555-561.

64. Ghosh, D.; Sawicki, M.; Pletnev, V.; Erman, M.; Ohno, S.; Nakajin, S.; Duax, W.L. Porcine carbonyl reductase - Structural basis for a functional monomer in short chain dehydrogenases/reductases. J. Biol. Chem. 2001, 276, 18457-18463.

65. Schormann, N.; Karpova, E.; Zhou, J.; Zhang, Y.; Symersky, J.; Bunzel, R.; Huang, W.Y.; Arabshahi, A.; Qiu, S.; Luan, C.H.; Gray, R.; Carson, M.; Tsao, J.; Luo, M.; Johnson, D.; Lu, S.; Lin, G.; Luo, D.; Cao, Z.; Li, S.; McKinstry, A.; Shang, Q.; Chen, Y.J.; Bray, T.; Nagy, L.; DeLucas, L. Crystal Structure of putative Tropinone Reductase-II from Caenorhabditis Elegans with Cofactor and Substrate. Protein Data Bank 2004, doi:10.2110/pdb1xhl/pdb.

66. Petit, P.; Granier, T.; d'Estaintot, B.L.; Manigand, C.; Bathany, K.; Schmitter, J.M.; Lauvergeat, V.; Hamdi, S.; Gallois, B. Crystal Structure of Grape Dihydroflavonol 4-Reductase, a Key Enzyme in Flavonoid Biosynthesis. J. Mol. Biol. 2007, 368, 1345-1357.

67. Luetz, S.; Giver, L.; Lalonde, J. Engineered enzymes for chemical production. Biotech. Bioeng. 2008, 101, 647-653.

68. Sambrook, J.; Fritsch, E.F.; Maniatis, T. Molecular Cloning: A Laboratory Manual; Cold Spring Harbor Laboratory Press: Cold Spring Harbor, NY, USA, 1989.

69. Friberg, A.; Johanson, T.; Franzen, J.; Gorwa-Grauslund, M.F.; Frejd, T. Efficient bioreduction of bicyclo[2.2.2] octane-2,5-dione and bicyclo[2.2.2] oct-7-ene-2,5-dione by genetically engineered Saccharomyces cerevisiae. Org. Biomol. Chem. 2006, 4, 2304-2312.

70. Larkin, M.A.; Blackshields, G.; Brown, N.P.; Chenna, R.; McGettigan, P.A.; McWilliam, H.; Valentin, F.; Wallace, I.M.; Wilm, A.; Lopez, R.; Thompson, J.D.; Gibson, T.J.; Higgins, D.G. Clustal W and clustal X version 2.0. Bioinformatics 2007, 23, 2947-2948.

71. Guex, N.; Peitsch, M.C. SWISS-MODEL and the Swiss-PdbViewer: An environment for comparative protein modeling. Electrophoresis 1997, 18, 2714-2723.

72. Sippl, M.J. Calculation of Conformational Ensembles from Potentials of Mean Force - an Approach to the Knowledge-Based Prediction of Local Structures in Globular-Proteins. J. Mol. Biol. 1990, 213, 859-883.

73. Arnold, K.; Bordoli, L.; Kopp, J.; Schwede, T. The SWISS-MODEL workspace: A web-based environment for protein structure homology modeling. Bioinformatics 2006, 22, 195-201.

74. Schormann, N.; Zhou, J.; Karpova, E.; Zhang, Y.; Symersky, J.; Bunzel, B.; Huang, W.Y.; Arabshahi, A.; Qiu, S.; Luan, C.H.; Gray, R.; Carson, M.; Tsao, J.; Luo, M.; Johnson, D.; Lu, S.; Lin, G.; Luo, D.; Cao, Z.; Li, S.; McKinstry, A.; Shang, Q.; Chen, Y.J.; Bray, T.; Nagy, L.; DeLucas, L. Crystal structure of short-chain dehydrogenase/reductase of unknown function from Caenorhabditis elegans with Cofactor. Protein Data Bank 2004, doi:10.2210/pdb1xkq/pdb.

75. Ghosh, D.; Wawrzak, Z.; Weeks, C.M.; Duax, W.L.; Erman, M. The refined three-dimensional structure of $3 \alpha, 20 \beta$-hydroxysteroid dehydrogenase and possible roles of the residues conserved in short-chain dehydrogenases. Structure 1994, 2, 629-640.

76. Tanaka, N.; Nonaka, T.; Tanabe, T.; Yoshimoto, T.; Tsuru, D.; Mitsui, Y. Crystal structures of the binary and ternary complexes of 7-alpha-hydroxysteroid dehydrogenase from Escherichia coli. Biochemistry 1996, 35, 7715-7730. 
77. Yamashita, A.; Endo, M.; Higashi, T.; Nakatsu, T.; Yamada, Y.; Oda, J.; Kato, H. Capturing enzyme structure prior to reaction initiation: Tropinone reductase-II-substrate complexes. Biochemistry 2003, 42, 5566-5573.

78. Grimm, C.; Maser, E.; Mobus, E.; Klebe, G.; Reuter, K.; Ficner, R. The crystal structure of 3 alpha-hydroxysteroid dehydrogenase/carbonyl reductase from Comamonas testosteroni shows a novel oligomerization pattern within the short chain dehydrogenase/reductase family. J. Biol. Chem. 2000, 275, 41333-41339.

79. Lukacik, P.; Kavanagh, K.L.; Oppermann, U. Structure and function of human 17- $\beta$ hydroxysteroid dehydrogenases. Mol. Cell. Endocrinol. 2006, 248, 61-71.

80. Pilka, E.; Guo, K.; Kavanagh, K.; Von Delft, F.; Arrowsmith, C.; Weigelt, J.; Edwards, A.; Sundstrom, M.; Oppermann, U. Crystal structure of 15-hydroxyprostaglandin dehydrogenase type1, complexed with NAD ${ }^{+}$. Protein Data Bank 2006, doi:10.2110/pdb2gdz/pdb.

81. Benach, J.; Atrian, S.; Gonzàlez-Duarte, R.; Ladenstein, R. The catalytic reaction and inhibition mechanism of Drosophila alcohol dehydrogenase: Observation of an enzyme-bound NAD-ketone adduct at $1.4 \AA$ resolution by X-ray crystallography. J. Mol. Biol. 1999, 289, 335-355.

(C) 2010 by the authors; licensee Molecular Diversity Preservation International, Basel, Switzerland. This article is an Open Access article distributed under the terms and conditions of the Creative Commons Attribution license (http://creativecommons.org/licenses/by/3.0/). 